\title{
Strategy Analysis and Model Construction of Virtual Teaching Research
}

\author{
Zhou Jie \\ Network Information Center, DaLian JiaoTong University, Dalian, China \\ E-mail: zj@djtu.edu.cn
}

Keywords: virtual teaching research; strategy analysis; model construction

\begin{abstract}
Compared with the traditional teaching research model, the virtual teaching research can change the state of the separation of teaching and research, promote the combination of knowledge and practice, change the teacher's growth environment, and create the opportunity for the outstanding teachers to come to the fore. At the same time, it can realize the sharing of digital teaching resources. In this paper, we start from the connotation of the virtual teaching research, and we analyze the strategy and construct a model of virtual teaching research.

With the continuous development of network technology and its wide application in the field of education, it has changed the teaching process and learning process. At the same time, it provides a new perspective for the research of education and teaching. The virtual teaching research is a new teaching research mode based on network technology.
\end{abstract}

\section{Connotation and advantages of Virtual Teaching Research}

Virtual teaching research is one of the models of the current teaching research. It is a new teaching research method with information technology widely used in the teaching. It is aimed to find problems, research problems, solve problems in the real situation of the school. It is a new teaching research mode, which can use modern information technology and constantly optimizes and improve the teaching and research of the means, process and structure, improve the teaching quality.

As a new teaching research method, the virtual teaching research breaks the limitation of time and space, and the communication and cooperation among teachers is greatly facilitated. At the same time, the network has been a breakthrough in the traditional teaching research face to face communication obstacles, help teachers to reflect and sum up; on the other hand, the virtual teaching research which is supported by network environment makes all levels of education workers have the opportunity to participate and expand the scale of teaching research activities in the use of network fast, timely. In addition, the virtual teaching research integrated video, audio, text, flash, pictures and other forms, greatly enriched the teaching content, and can improve students' learning interest.[1]

\section{Strategy Analysis of Virtual Teaching Research}

The success of virtual teaching research is closely related to the design and development of the system. At the same time, how to mobilize the teachers to participate in the virtual teaching is the key to the success of the virtual teaching research.

\section{Establishment of the Virtual Teaching Research Team}

The virtual teaching research team is mainly composed of the subject teachers, subject experts, teaching researchers and other relevant personnel in the region. In the course of the activity, each member is the main body, equal participation in the whole teaching research activities. Subjects can be selected according to the teaching key points and difficulties and knowledge points which students can be interested. To collect relevant learning materials; contact the relevant subject matter experts; and invite relevant personnel to actively participate in the virtual teaching research activities. The organized activities with plan are very important in the beginning of the development 
of virtual teaching research. With the gradual expansion of the virtual teaching research, it will gradually transit to the free organization. while the teachers who participate in virtual teaching research obtain the real results, other teachers can organize their own form and form their own small teams. Of course, the theme will be a variety of forms of activities Only in the participation of the virtual teaching of teachers in the teaching and research activities to bring real results, in order to make it become a spontaneous, self organization form. Of course, the theme will be a variety of forms of activities. That will bring all flowers bloom together and contention of a hundred schools of thought.[2]

\section{Provide Network Technical Support for Teachers}

In the process of using virtual teaching research platform to teaching and research, the traditional discipline teachers, especially the older teachers worry about the lack of information literacy which can be difficult to control. Some common platforms and tools are accepted and respected by the public. The most important is to operate easily and to use a simple method. This is an important reason for the popularity of teacher blog. Therefore, schools and educational institutions often to carry out teacher training in information technology skills to enhance the teacher`s information literacy, clear up the fear which teachers face the perplexity of network technology. At the same time, the manager should also provide technical consultation service to the general teachers, and constantly stimulate teachers use virtual teaching research platform to carry out a full range of teaching research work.

\section{Establish Long-term Incentive Mechanism to Meet the Needs of Teachers in the Material and Spirit}

According to the reinforcement theory of behavior psychology, effective motivation is a driving force, which reflects the recognition of the former behavior or the first phase behavior, and can effectively guide the actors to continue and improve their own behavior. Therefore, the virtual teaching Research on Teachers' participation in the situation should be recorded, based on this record can be commended and rewarded, and can be used to encourage teachers to actively participate in the virtual research, project can be not only used as a teacher's teaching research results for future Evaluation, but also can get some financial support, is bound to greatly encourage teachers to participate in the enthusiasm and initiative.

\section{Create Excellent Teaching Research Network Resource Environment}

Can be led by the disciplinary education experts, to different levels of teacher studio as the starting point, to based Teachers' participation, supplemented by the necessary information technology platform, so that it can establish a stable pyramid type of teaching and scientific research mechanism, virtual research was to achieve ecological sustainability, as a result of this teaching research mode with effectiveness. Only with the effectiveness, will have the appeal, will have inexhaustible vitality.[3]

\section{The construction of virtual teaching and research model}

\section{Construction Strategy}

\section{Target strategy:}

For the problem that teachers in the process of teaching and research are not clear how to carry out research activities, and collaborative task is not clear, we can use the target strategy, the strategy is before every specific research activity carried out, the teachers need to clearly understand the target, the specific tasks, as well as the way to complete the task, the performance form of the achievements and so on, it is very important for carrying out collaborative research smoothly. The target strategy is not only used before the teaching and research activities, but also in the process of teaching and research activities, to ensure that teachers are always toward the ultimate goal of the activities. 


\section{Incentive strategy:}

Through the interview we know that teachers think it should reflect the situation of each teacher in the teaching and research activities in a timely manner, which can not only give a positive to the teacher, but also inspire other teachers to participate in the enthusiasm. In view of this problem, we can take the "incentive strategy", through the adoption of some incentives, such as "integration", the achievements of the teachers can be sure, so as to stimulate the enthusiasm of teachers.

\section{Collaborative strategy:}

Teachers mostly show lack of coordination skills, not knowing how to work with others, which is due to no connection and lack of communication among teachers, we can use some "cooperation strategy", through organizing some activities to promote teachers to establish a connection, and through the design of effective research content and the timely guidance from the steering group to promote teachers to further cooperation, The implementation of the strategy has laid a foundation for the development of research activities.

\section{Guiding strategy:}

For the problem that teachers lack of support and guidance, all kinds of problems can not be solved in time, we adopted the "guiding strategy". Manager can track and guide throughout the whole process, and give answer in time to the problem appearing in the teachers QQ group; for the exchange in the teachers forum, give timely feedback and evaluation; for the discussion which deviate from the topic, in a timely manner to point out and guide, so as to ensure the smooth and effective development of teaching and research activities.

\section{Implementation Process of Virtual Teaching Research(figure 1)}

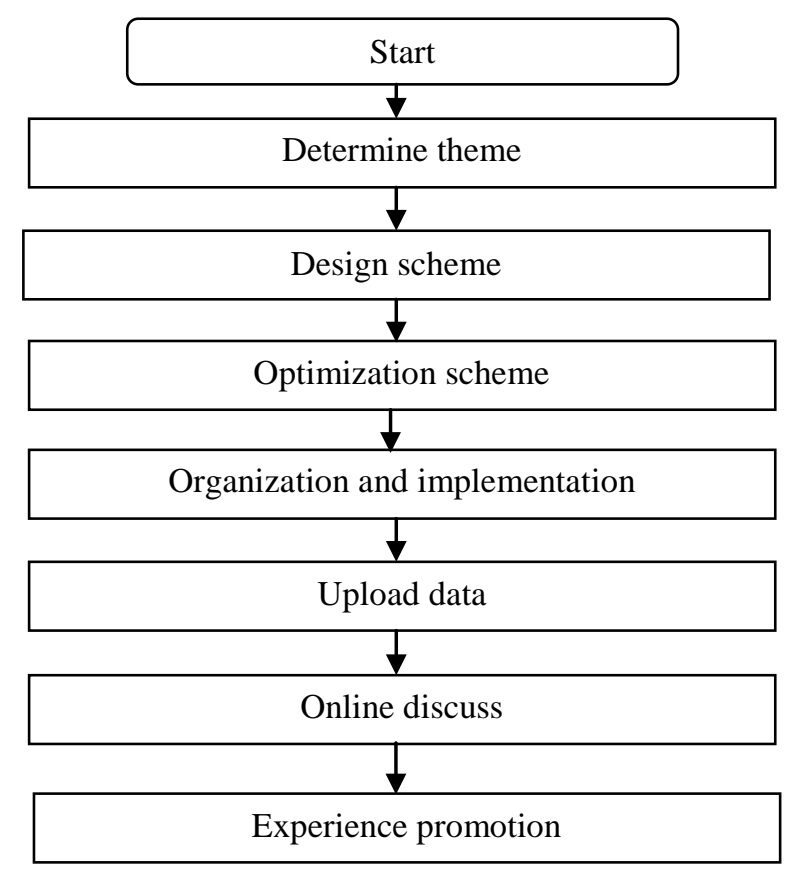

\section{Determine theme:}

Figure 1. Implementation Process of Virtual Teaching Research

The content of teaching research is often derived from the practical problems encountered in daily teaching. Therefore, the teaching research activities should have a strong awareness of the problem, and be good at combining with practical problems in teaching research. Then promote the problem to studying theme, clear division of labor, determine the basic research ideas, make research plan. The method and means of solving the problem is obtained through the standard teaching research and practice.

\section{Design scheme:}

According to the determined theme and ideas, we need to design a targeted research program, and continuous correction and improvement in the practice. First of all, it should carry out the purpose of the study of the theory of education and related topics of theoretical study for complete 
the research effectively. Through virtual teaching research bulletin board, monographic study, forums and other plate, regularly publish teaching cutting-edge information for teachers to take an elective. Secondly, play a leading role, that is, through the expert consultation, the integration of multi resources, to help teachers to solve puzzles and problems, to avoid the loss of direction in the practice process, improve research efficiency. Finally, carry out the collective discussion among the group and the whole staff, collective wisdom.

\section{Optimization scheme:}

Teaching problem is becoming more and more complex. The design of the research project must also be diverse and targeted, and in the process of continuous improvement in practice. First, the research program was published in the online bulletin board, to provide all the teachers, to give full play to the collective wisdom. Secondly, with the teaching material and the teaching outline as the standard, combined with other people's opinion, the main implement of the plan will redesign the original research project and make it more feasible and practical.

\section{Organization and implementation:}

According to the optimized plan, organize teachers to develop the personal practice research. In the teaching, the teacher according to the actual situation of the plan to promote the implementation, and summarize the periodical results timely. The implementation of the process is the behavior of the individual, but also the team's collaboration, to help teachers to reflect on and improve the quality of teaching.[4]

\section{Upload data:}

Virtual teaching research is the complementary way of combining the online teaching research and traditional teaching research. No matter what kind of conventional teaching research methods, in the preparation, improvement, implementation process can form the accumulation of information or results uploaded to the online teaching research platform at any time, so that the end of conventional teaching research activities it can still help more people to continue to participate in deeply.

\section{Online discuss:}

Teachers should reflect in the teaching process. They can through writing teaching essay, reflective teaching, case teaching, cases and lesson study, teaching article to improve the level of self reflection and teaching research. At the same time, the teachers' teaching design, teaching resources, and guide the students to work, lesson record and Reflection on the teaching content is released in time to the Internet, to form the database of teaching resources. Improving the traditional teaching research activities, because of the content, time and other conditions, it is difficult to achieve full participation, and the number of speakers is limited, and teaching research data backup difficult, more difficult to share.

And through the network, it can not be restricted by all these factors, truly realize the equality exchange. All the teachers have full balance of communication opportunities. Using the network to realize the sharing of education and teaching resources which is the biggest advantage of the teaching research.

\section{Experience promotion:}

The experience and results obtained from the teaching research activities are ultimately for the teaching service. First, focus on some hot issues, organize some teachers or experts in the lesson study were comment or lead, to achieve effectiveness of the application. Second, relying on the "online teaching research platform" to organize the teachers to discuss the key issues in the case, sum up the valuable teaching experience or problem solving methods, help teachers to find out the shortcomings to improve.[5]

\section{Network Platform}

Network platform includes forums, blogs, QQ, and special topics. They are the supporting platform for virtual teaching research. Various forums and blogs are simple and easy to operate, and the virtual teaching research is based on the network platform which has been widely used; the strong function of the QQ group also provides a powerful platform for network research. 
By the strategy, process and platform build a model of virtual teaching research. (figure 2)

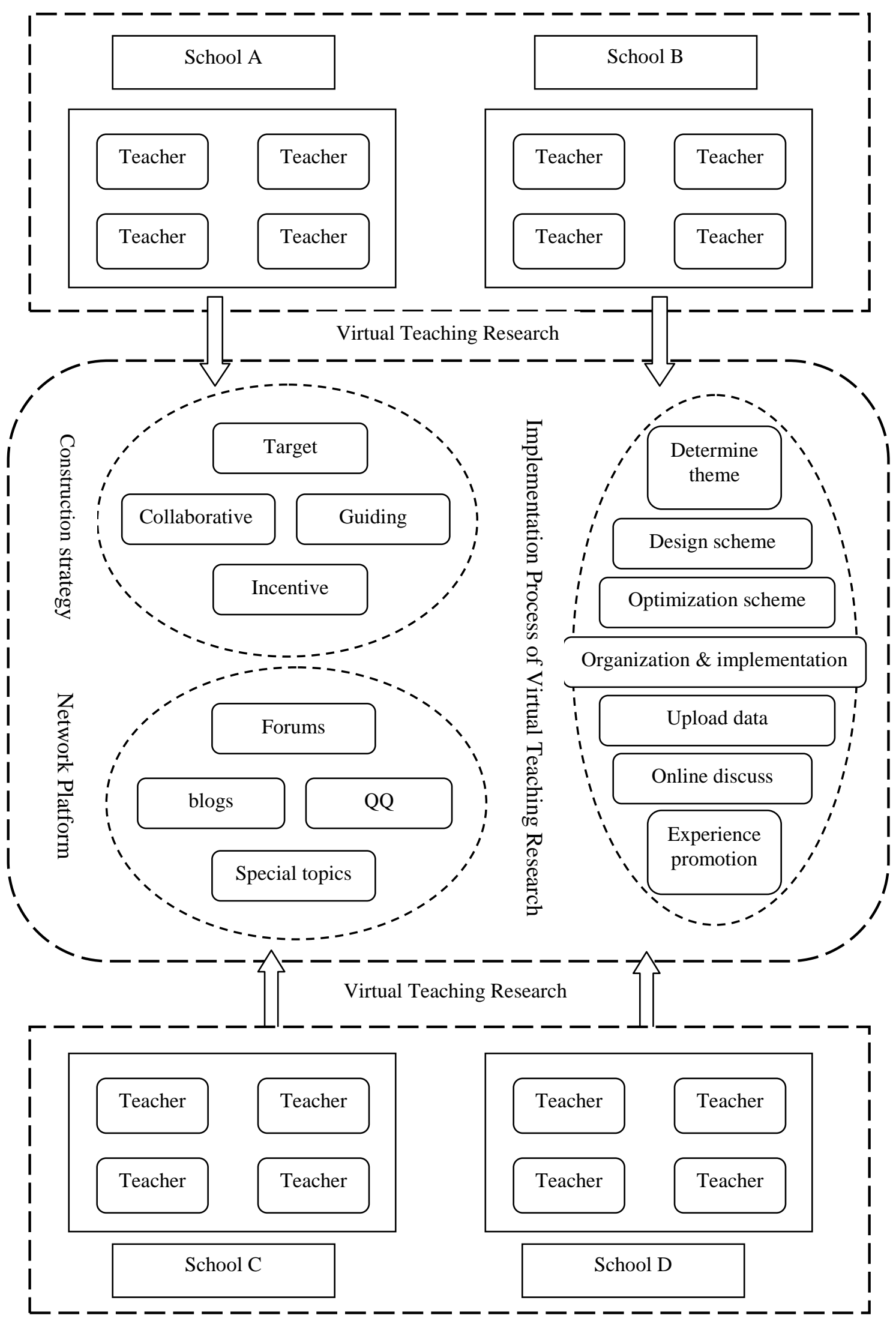

Figure 2. Virtual Teaching Research Model. 


\section{Problems and Prospect of Virtual Teaching Research}

As the Keep up with the times teaching research method, the virtual teaching research method has some advantages in resource sharing, communication environment and guiding. It is a continuation, development and a useful supplement of traditional teaching research. But at the same time there are some problems.

\section{Existing Problems}

\section{Lack of sustained participation enthusiasm:}

Virtual teaching research with its cross time and space, participation in democratic characteristics should become the place which teachers can speak freely, but only a few of the teachers are often frequent and most teachers often stealth. They often come to this platform to query policies and regulations. Teachers come here more to download resources and not to exchange. So the problem is coming. One is difficult to maintain the enthusiasm of teachers' continuous participation, is not conducive to mobilize the enthusiasm of the majority of teachers to participate in the virtual teaching research. On the other hand, it will greatly affect the popularization process of virtual teaching research. It can be said that the improvement of the degree of teacher`s participation has become a key factor in the progress of the teaching research.[6]

\section{Deep exchange interaction is not enough:}

Improve the effectiveness of the virtual teaching research, not only to attract more teachers to participate in it, but also to make the in-depth discussion of the problem. However, in the present, the interaction between teachers is still in shallow and moderate levels, on the blog platform, some teachers focus on their own writing, rarely care about the depth of thinking with others. How to stimulate the virtual teaching research in the depth of the teacher exchange? Some scholars have pointed out: on the one hand, we should adopt the theme of practical teaching research, the activity of a subject can lead to the teacher's thinking. On the other hand, it should be aimed at the problem of real education teaching, and the problem is to stimulate the engine of thinking.

\section{Lack of collaboration resources:}

At present, many teaching research sites have paid enough attention to the construction of educational resources, and provide navigation, information retrieval, resource upload and download. However, the resource is lack of exchange, most of the articles published are the teachers' personal teaching knowledge. It is also difficult to form effective teaching resources for teachers to use in practice, which is an important factor affecting the progress of Virtual Teaching research. Resources construction of virtual teaching research not only to embody the spirit of sharing, but also is a kind of optimization. With the teacher`s wisdom, the creation of high quality resources and services to improve the teachers' the wisdom of the crowd.

\section{Prospect}

As a beneficial supplement of traditional teaching research, it is playing a beneficial supplement to the research of its advantages. First of all, we should set up the right idea. The integration and utilization of the resources of the different Departments can better promote the virtual teaching research. Effective teacher incentive and evaluation mechanism is the system guarantee for the sustainable development of virtual teaching research. Virtual teaching research not only needs a number of high information literacy teachers team, but also need leaders which from regional education department to join to promote the development of virtual teaching.

\section{References}

[1] Fang Fang and Shen Jing, "Design and implementation of web based on Data Structure”,Journal of AnQing Teachers College (Natural Science Edition) 2013.02

[2] Liang Wenchang, “Some knowledge about network teaching and research”, China, 2011.11

[3] Zhong Chunlei, "The present situation and analysis of network teaching research under the blog environment”,Software Guide(education technology) 2010.10 
[4] Zhang Chao, "The reform of teaching and research method based on Network Environment", "Journal of Hebei Normal University (education), 2012.07

[5] Shi Cunsheng, “Theory and research of network teaching research”,Journal of HeiLongjiang College of Education 2010.10

[6] Yu Haitao,An Hongtao and Wang Jun, "Research on the effective implementation of the network teaching research for teachers` professional development”, China Educational Technology 2007.01 